\title{
Algumas notas sobre as leituras de obras literárias digitais
}

Alckmar Luiz dos Santos* | Universidade Federal de Santa Catarina

Resumo: O meio digital, como é já notório, alterou qualitativa e quantitativamente a materialidade das obras que nos pomos a ler. Este artigo propõe que, para ler criações digitais, não basta ser alfabetizado e ter noções medianas de computadores e de redes. Há uma complexidade a ser desenvolvida, uma sofisticação a ser cultivada por esses leitores, quando se intrometem pelo espaço digital adentro.

Palavras-chave: Mallarmé, programação digital, Melo e Castro.

un livre ne commence ni ne finit : tout au plus fait-il semblant

Mallarmé, Le Livre

Vieira falava do engenho de açúcar como um "doce inferno". Freqüentemente, a leitura de obras em meio digital nos faz pensar nessas leituras e nesse meio como um emocionante inferno, tal a legião de significantes, movimentos, gestos, imagens e interações que somos chamados a buscar, a explorar, ou a propor. De fato, essa pluralidade de significações

* Alckmar Luiz dos Santos - UFSC - Núcleo de Pesquisas em Informática, Literatura e Lingüística. Pesquisador do CNPq. 
possíveis, de interpretantes e de significados, isso tudo que, na tradição escrita e impressa, era um dado implícito e que permanecia em geral como pano-de-fundo de qualquer leitura, extravasou seus limites e multiplicou as instâncias de significação, os campos de sedimentação de sentidos e até mesmo os próprios significantes. Em outras palavras, o meio digital, como é já notório, alterou qualitativa e quantitativamente a materialidade das obras que nos pomos a ler. E não estamos aqui nos referindo aos constantes desleixos de programadores visuais, empenhados em multiplicar ad nauseam as figuras, os ícones, as interações, os pluguins, os campos php etc. Casos extremos assim apenas ilustram derrapagens que ocorrem devido ao excesso inerente aos meios digitais e às obras literárias que por eles transitam.

Podemos, como exemplo, tomar um gerador automático, o Sintext de Pedro Barbosa (disponível em http://cetic.ufp.pt/sintext.htm). Ao lançarmos a geração de "Didática", obtemos como resultado:

Vai ler uma sucessão automática de aforismos

$\mathrm{e}$

fórmulas publicitárias experimentais em modo de demonstração.

O texto será gerado electronicamente sem qualquer interrupção...

Se pretender gerar o texto em ciclo infinito active o botão respectivo.

Texto generativo

concebido e realizado por

Pedro Barbosa

utilizando o Sintetizador de Texto Automático:

versão Web - 1.1

desenvolvida por José Manuel Torres

1999

(Centro de Texto Informático e Ciberliteratura)

1. No caso, é importante compreender a distinção entre excesso e excessivo que proponho em Leituras de Nós. (São Paulo: Instituto Itaú Cultural, 2003). O excesso seria a maneira de tirar proveito do caráter excessivo que se encontra freqüentemente nos meios digitais; se não fosse assim, estaríamos submergidos por uma hiperinflação informacional e impedidos de uma apropriação efetiva dos meios digitais e da obra com que se interage nele. 
Belo Horizonte, p. 1-232

Disponível em: bttp://www.letras.ufmg.br/poslit

a partir do SINTEXT para DOS criado anteriormente

por Abílio Cavalheiro \& Pedro Barbosa

1995

<DIDÁCTICA>

(variações electrónicas)

Para perguntas arrogantes, perguntas em êxtase.

Quem faz perguntas cansadas, recebe respostas submarinas.

A excelência do saber está na paixão de saber perguntar.

O aluno faz perguntas exactas, o professor remói respostas na água.

Grande é o saber do mestre que aprende o que não se pode aprender.

Quem faz perguntas impertinentes, recebe respostas iracundas.

O aluno faz perguntas exactas, o professor remói respostas impertinentes.

Grande é a sapiência do mestre que aprende o que não se pode ensinar.

A excelência do saber está na arte do interrogar.

O aluno faz perguntas vomitadas, o professor remói respostas terrestres.

Grande é o saber do mestre que ensina o que não se pode aprender.

As frases podem deixar de aparecer quando se clica sobre o botão <Parar Geração de Texto>. Mais acima dessas frases geradas automaticamente, em outro quadro, o dispositivo permite a leitura da programação que dá origem a essa geração automática de frases. Trata-se de uma quantidade muito grande de linhas e de comandos, mas uma pequena parte delas pode ser aqui reproduzida, a título de exemplo:

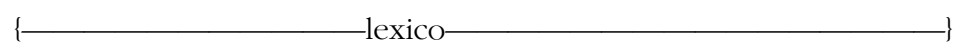

[frase["O aluno faz perguntas "[1[“cansadas "]1]", o professor remói respostas "[2["distraídas "]2]". "]frase]

[frase["Quem faz perguntas "[1["cansadas "]1]", recebe respostas "[2["distraídas "]2]". "]frase]

[frase["Para "[3["perguntas "]3][1["cansadas "]1]", "[3["respostas "]3][2["distraídas "]2]". "]frase]

[frase["Douto é "[nom1["o professor "]nom1][atr1["que ensina "]atr1][atr2["pelo prazer "]atr2][atr3["de aprender"]atr3]". "]frase] 
[nom1["o mestre "]nom1]

[atr1["que aprende "]atr1]

[atr2["com a paixão "]atr2]

[atr3[“de ensinar"]atr3]

[atr3["de interrogar"]atr3]

[frase["Grande é "[nom2["o saber d"]nom2][nom1["o professor "Inom1][atr1["que ensina "]atr1][atr4["o que não se pode ensinar"]atr4]". "]frase]

Com isso, já temos no mínimo dois conjuntos de significantes que podem se submeter a nossa leitura. E leitura, no caso das linhas de programação, pode ser apenas a constatação do que foi feito pelos programadores, ou seja, uma inspeção dessas tais linhas. Ora, essa leitura também pode ser exercida de forma mais atuante, tornando-se então uma interferência direta nossa, ao alterarmos elementos ou trocarmos seqüências de programação. Mas, nesse caso, o que seria leitura, não se estaria tornando escrita? O que era apenas constatação passiva, não estaria se transformado em interferência direta e autoral? E ainda: como dar conta das inúmeras possibilidades de justaposição e de interferência entre 1) os aforismos gerados automaticamente, 2) as interpretação que nos permitimos fazer deles, 3) a compreensão maior ou menor das lógicas de programação postas à nossa disposição, 4) nossas modificações nessa programação 4) as interpretações que fazemos dos significantes gerados por nossa própria programação?!

Otávio Guimarães Tavares ${ }^{2}$ fez alguns exercícios de leitura e de reprogramação, dentro do Sintext. Num deles, utilizou versos do Paradise Lost de Milton e o resultado foi:

$<$ IN SEARCH OF PARADISE $>$

(with the fragments of the same)

Of all those myriads which we lead the chief;

Driven by a keen north-wind, that, blowing dry,

Left him at large to his own dark designs,

With floods and whirlwinds of tempestuous fire,

And after him, the surer messenger,

2. Membro do Núcleo de Pesquisas em Informática, Literatura e Lingüística (NUPILL). 
Pavilions numberless, and sudden reared,

Thy sleep dissent? New laws thou seest imposed;

Of unblest feet. Him followed his next mate;

Prone on the flood, extended long and large,

With ever-burning sulphur unconsumed.

In billows, leave i' th' midst a horrid vale.

Thus Satan, talking to his nearest mate,

Breaking the horrid silence, thus began:-

Would never from my heart: no, no!I feel

..........

He looked, and saw the ark hull on the flood,

Bad influence into the unwary breast

With floods and whirlwinds of tempestuous fire,

On the other side Adam, soon as he heard

Quaff immortality and joy, secure

From standing lake to tripping ebb, that stole

Cast out from God and blessed vision, falls

As linhas de comando inseridas no campo de programação do

Sintext foram:

[texto[

“ In one moment, Paradise was lost

Lost beyond the reaches of man

Keept before the stars of his dreams

But, in an age where technology reaves with undaing streght, awaiting to consume all humanity

perhaps, within the fragment of a moment

we may find a piece of what was lost

<IN SEARCH OF PARADISE>

(with the fragments of the same)"

“

[ciclo000x7[

[frase["Of Man's first disobedience, and the fruit "]frase]

[tira-frase[

" 
O eixo e a roda: $v .13,2006$

Disponível em: bttp://www.letras.ufmg.br/poslit

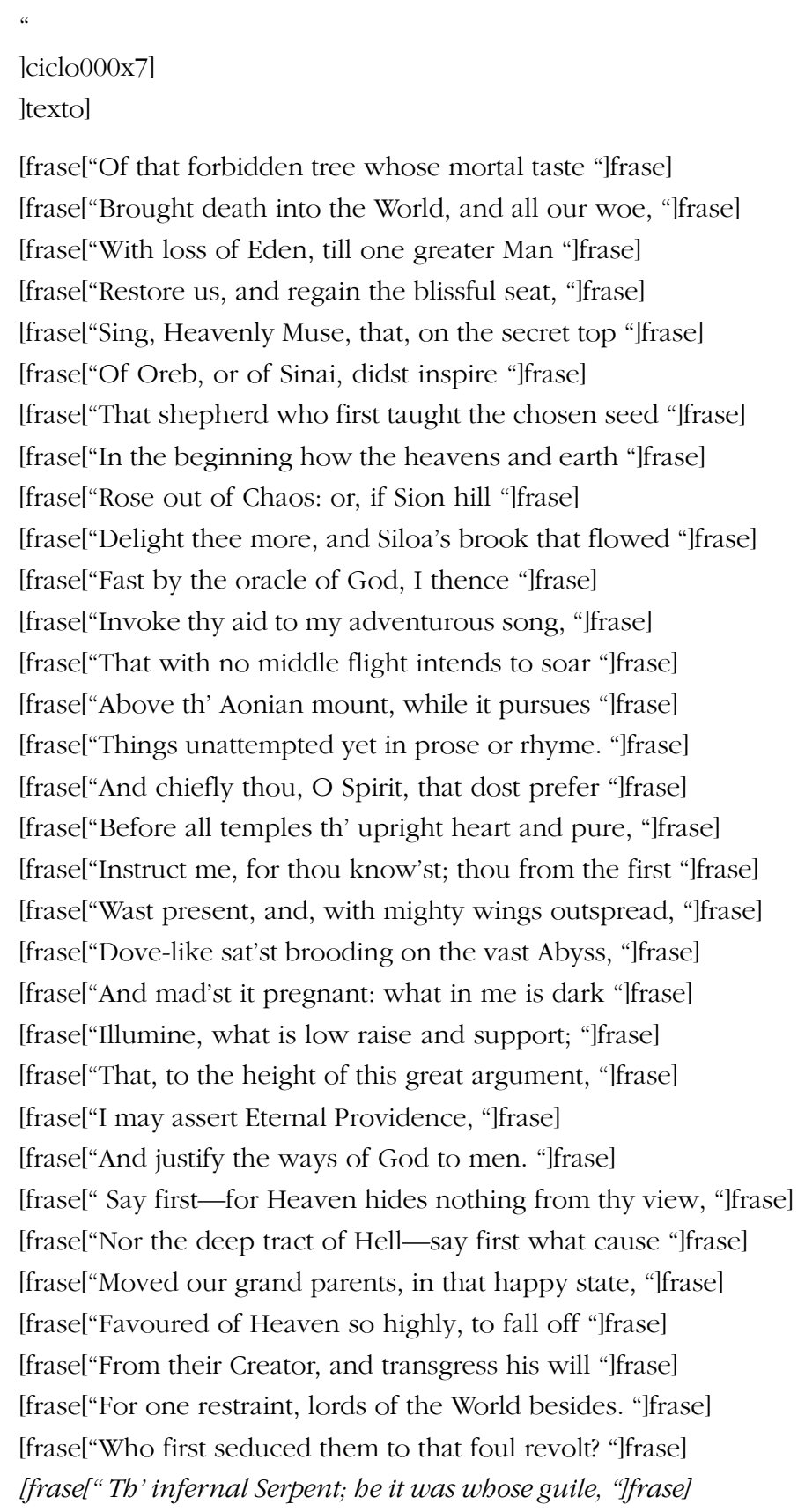


Ora, não é apenas no Sintext que aparecem essas possíveis e inúmeras conjunções entre as instâncias submetidas a nossas leituras (os significantes que resultam da programação, a própria programação, as lógicas e estratégias de interação com o objeto etc.). Em qualquer criação digital, essas leituras e essas intervenções podem se tornar o foco principal das leituras, dependendo, em maior ou menor grau, das estratégias do programador-criador e, também, do conhecimento e da habilidade do leitor. É justamente a partir disso que Xavier Malbreil propõe que as leituras de obras literárias criadas na internete também passem pela análise do código-fonte em HTML. ${ }^{3}$ Isso demonstra que, para essas criações digitais, não basta ser alfabetizado e ter noções medianas de computadores e de redes. Há uma complexidade a ser desenvolvida, uma sofisticação a ser cultivada por esses leitores, quando se intrometem pelo espaço digital adentro. Sem que tenham de ser programadores, nem especialistas em programação visual, sem que conheçam obrigatoriamente os comandos e as sintaxes do HTML, eles terão de desenvolver e especializar suas sensibilidades e suas habilidades para poderem examinar linhas de código, para compreender grosso modo estratégias e estéticas de programação, abrindo caminho para suas próprias interferências, para sua apreensão efetiva da obra.

Ora, constatamos aí a evidência de uma duplicidade: num espaço, o da obra disposta na tela do computador, temos uma primeira página (ou tela) que podemos chamar de visível, com suas linguagens de formas, suas interações, suas espessuras icônicas, seus movimentos de transformação, adaptação e interatividade; num outro espaço, o dos editores de linhas de programação - espaço de outra visibilidade -, temos o código-fonte, justamente o que torna aquela primeira página visível, manipulável e, conseqüentemente, dotada de algumas coerências. Ora, essa duplicidade entre os dois espaços não se reduz a dicotomias maniqueístas, não se ancora em desvãos imobilizados e imobilizantes (traduzidos em modismos como entrelugar e outros); nem se resolve em dialéticas de superação, seja platônica, seja hegeliana. Essa duplicidade, como acontece à maioria delas no meio digital, nem mesmo pode ser organizada em uma diacronia de sentido único e

3. Na conferência intitulada Méthodologie d'approche critique de oeuvres de littérature informatique, no colóquio L'internet littéraire francophone, realizado no Centre Culturel international Cerisy-la-Salle, de 13 a 20 de agosto de 2005. 
permanente: de uma a outra, ou de outra a uma, não se consegue impor um único sentido temporal. Com efeito, essa indecidabilidade é da mesma ordem da indefinição inaugural entre 0 e 1 na linguagem binária: não há qualquer anterioridade de um com relação a outro. É assim que, no pólo do criador, quando se programam efeitos, aparências, disposições e estratégias, quando se acumulam significantes e estratégias de interatividade, nunca se pode determinar que o espaço da escrita de programação - o código-fonte - é a instância inaugural das telas que virão a seguir; sempre haverá sobras e lacunas que vão tecendo complexas relações de distanciamento e de contigüidade entre a página visível (essa a ser submetida à manipulação de algum leitor) e as linhas de programação. E, no pólo do leitor, da mesma maneira, nunca se estará suficientemente além das linhas de programação: em toda leitura da página visível, em qualquer interação, no deslizar do cursor sobre a tela, no arrastar de ícones de um ponto a outro, na inserção de dados, nos gestos de clicar e de soltar, sempre arrastamos conosco - nas trajetórias de nossas decisões e indecisões, nas entrelinhas de nossos movimentos - sempre arrastamos conosco as linhas de comandos, as escolhas de linguagem de programação, as imposições dos compiladores, as restrições das linguagens de máquina. Em outras palavras, o código-fonte está, ao mesmo tempo, contíguo às e afastado das páginas visíveis. E ainda, o modo como essas contigüidades e afastamentos serão desenhados vai depender não apenas de como as páginas visíveis são construídas e de como as linhas de programação são escritas. Dependerá também da habilidade de cada leitor em criar espaços e percursos de relações entre páginas visíveis e programações.

O Livre de Mallarmé nos dá algumas indicações interessantes de como tentar movimentos de reflexão e de compreensão nessa pluralidade inumerável de significantes e de significações do espaço digital, nessas hesitações entre um programa de geração de significantes e os próprios significantes gerados. Apesar de essa aproximação entre o Livre e o espaço digital não ser nada inédita, algumas conclusões interessante e até surpreendentes ainda podem ser tiradas dela. Jacques Schérer, na edição que preparou da obra de Mallarmé, ${ }^{4}$ afirma que:

4. Le "Livre" de Mallarmé. Paris: Gallimard, 1977. 
La dualité est l'indice et le moyen de l'ordre qui se construit à partir du chaos. (...) les constantes réduplications du Livre veulent être démonstratives et créatrices. Ce n'est un vain souci esthétique que le Livre confronte si souvent "deux poèmes".

Em nosso caso, à semelhança dessa dualidade do Livre (tal como a apresenta Schérer), também uma série de dualidades, desentranhadas das leituras da obra digital, poderiam vir impor uma ordem ao nosso caos informático: obra e texto; processo produtor e elementos produzidos; geração e leitura de significantes; utilização das programações e leituras dos comandos programados; programador e criador; leitor e autor etc. De fato, essa lista parece ser interminável. Todavia, não são dualidades que se confrontem e se resolvam num mundo em que "tudo existe para chegar a um livro" (pois este daria a ilusão de ser o ponto de chegada, o limite assimptótico, a pretensa síntese final dessas dualidades). Ora, talvez se trate de dualidades que justamente não devam ser resolvidas, nem submetidas a qualquer princípio unificador. Aliás, qualquer tentativa de redução dialética seria tão aporética quanto a união substancial cartesiana entre corpo e alma. Nas obras digitais, parece não haver nada de união, nada de substância única. Assim, em vez do "duplo enganador" do Livre, teríamos, de fato, dualidades reveladoras. Mas não reveladoras de uma redução a princípios de ordem racional ou de necessidade metafísica; elas são reveladoras de uma caoticidade que lembra, muito de perto, a ciência do caos, aquela para a qual o mundo seria o resultado de um determinismo sem previsibilidade. ${ }^{7}$ Contudo, é o mesmo Schérer quem descreve muito bem essa dinâmica de dualidades, falando ainda do Livre de Mallarmé:

... le terme de dualité (...) n'est ni une identité ni une contradiction de deux objets. La meilleure formule, sinon pour la définir, du moins pour l'approcher,

5. Id. p. XVIII.

6. Schérer afirma que Si tout est double, tout est trompeur et le "deuxième fond"évoqué plus loin, s'il n'est celui d'où le prestidigitateur tire un lapin de son chapeau, est du moins le point de départ d'un espace où retentit un écho - double par définition - et qui est décrit contradictoirement comme le théâtre le plus traditionnel. Id. p. XXI.

7. BOUTOT, Alain. La Philosophie du Chaos. Revue Philosophique de la France et de l'Etranger, n. 2, avril-juin. Paris: PUF, 1991, p. 171. 
O eixo e a roda: $v .13,2006$

Disponivel em: http://www.letras.ufmg.br/poslit

est une image mallarméenne : celle du pli. Un pli ne divise pas une feuille en deux moitiés identiques, ni même distinctes. Il sépare sans séparer. Il inaugure des éléments qualitatifs, puisqu'en créant au moins deux rectos et deux versos il est le point de départ d'une différenciation qui en se répétant peut, par une suite arithmétique rapide, mener très vite à des nombres très grandes. C'est bien pourquoi l'image du pli est centrale dans la thématique mallarméenne comme dans la structure du Livre. Elle respecte la réalité (la feuille pliée reste intacte) mais en permet l'évolution : le livre et le Livre naissent du pli. En d'autres termes, elle repose sur une notion dialectique.

Talvez fosse necessário fazer um único reparo: o adjetivo "dialética", ao final, parece-me conflitante com o que Schérer disse antes, ao mencionar dualidades que não se resolvem com as sínteses habituais. E explico: quando fala de dobra, ele menciona aquilo que "separa sem separar", lembrando de imediato a fita de Moebius. Nesta, a indecidabilidade espacial (o que seria nela externo e interno?) se faz acompanhar de uma indefinição temporal (onde estariam nela início e fim?). De fato, a fita é um artefato de simplicidade aterradora: com uma pequena torção (ou dobra), ela parece romper quaisquer barreiras entre tempos, entre espaços, e entre tempo e espaço. E ainda, faz lembrar, muito de perto, vários dos mecanismos do meio digital. Assim como a fita de Moebius e o Livre de Mallarmé (nessa descrição que Schérer faz dele), esse meio também parece tornar impossível diacronias e sincronias definitivas, com sentido único; afasta toda e qualquer hierarquia irrevocável entre seus elementos e operações; não se dobra, enfim, a sínteses dialéticas.

Em outras palavras, estamos tentando descrever aqui uma ontologia negativa, uma série de impossibilidades para o espaço digital: 1) nele, parece não haver tempo nem lugar para uma sincronia de sentido único entre seus vários elementos; 2) não se estabelece proeminência alguma de um elemento com respeito a outros; 3) não se vê surgir nenhuma diacronia que imponha uma seqüiência imutável e rígida entre os vários elementos e operações, que não possa ser retomada ou alterada depois de estabelecida uma vez; 4) não se pode impor uma precedência definitiva de um elemento com relação aos outros.

8. Op. cit. p. XXII. 
Todavia, é fato que qualquer pessoa não terá dificuldades em associar sentidos,

proeminências, seqüiências e precedências, tanto à criação, quanto à leitura de obras digitais. Basta cravar seus referenciais de tempo ou de espaço em algum ponto do objeto ou da leitura e, a partir dele, estabelecer, por exemplo, que a escolha das técnicas de permutação e de combinação no Sintext, parecem ter sido o ponto de partida da criação, ao impor escolhas de linguagens e ambientes de programação, ao predeterminar estratégias que vão da construção de elementos lógicos à escolha de certas palavras e frases (em detrimento de outras). Ou ainda, é perfeitamente legítimo que o leitor determine sua ancoragem no texto sendo lido, priorizando os campos vazios a serem preenchidos (pelo leitor e pelo sistema) e as instruções que vão sendo seguidas, e determine aí a gênese do sentido, o início da seqüência, o elemento proeminente, a instância que precede todo o resto. Essa apelo ao empírico parece desmentir o que foi dito no início deste parágrafo. Porém, examinemos isso mais de perto.

Partindo dessa perspectiva, há perguntas que não podem ser respondidas de modo imediato e claro: até que ponto, sentidos, proeminências, seqüências e precedências associados à obra e ao texto digitais são sempre os mesmos, do lado do objeto produzido e do lado de sua produção? Como se pode afirmar que, a cada releitura, sentidos, proeminências, seqüências e precedências se mantêm inalteráveis, do lado da obra e do lado do texto? Ainda: o que nos garante que aquilo que estabelecemos no texto surgido e surgente da leitura é o mesmo que vamos encontrar, biunivocamente, na obra? É claro que não se pode garantir nada disso, em qualquer obra artística, sobretudo em obras digitais! Temos, de fato, uma indecidabilidade que, inaugural em todo texto, atingiu em cheio a obra (quer dizer, sua materialidade) digital, indecidabilidade que nos impede de propor a solução das inúmeras dualidades do espaço digital por meio de uma pretensa união substancial, de uma cômoda síntese dialética, de uma hierarquização derradeira.

E o mais perturbador para essas buscas de ordem, para essas tentativas de conciliar as várias dualidades do espaço digital, é justamente a associação entre quantitativo e qualitativo. No trecho transcrito acima, Schérer dizia do Livre que ele "inaugure des éléments qualitatifs, puisqu'en créant au moins deux rectos et deux versos il (...) peut, par une suite arithmétique rapide, mener très vite à des nombres très grandes." Ao associar qualitativo a quantitativo, contudo, não se faz a Aufhebung deste para chegar àquele. Tanto no Livre, quanto no espaço digital, quantitativo e qualitativo podem coexistir, 
cada um em sua própria esfera de significação, sem se reduzirem um a outro, mas sem que um deixe de influenciar, alterar, reduzir ou expandir o outro. Eles são como grandezas vetoriais, que não podem ser somadas a não ser no espaço intermediário entre elas, como no esquema abaixo (simplificado para duas dimensões):

De fato, a cada momento em que inspecionamos as estratégias de

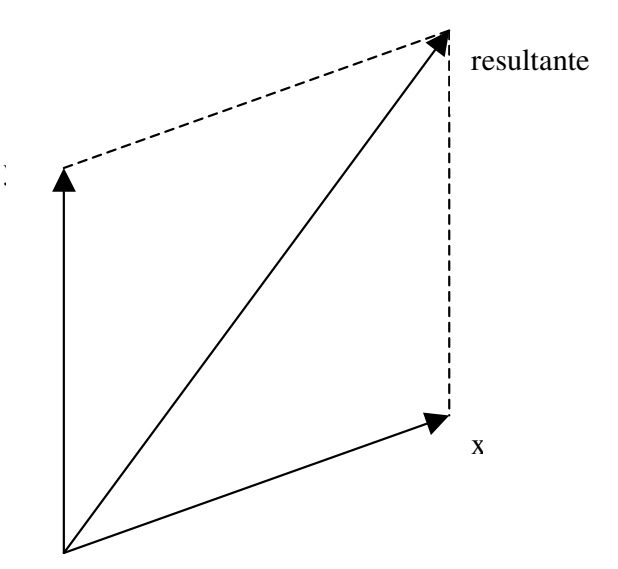

produção dos significantes e os próprios significantes, surgem os aspectos quantitativo e qualitativo, sob perspectivas diferentes mas sempre contíguas. É como se, em cada frase curta que emerge do Sintext, essa limitação de palavras encontrasse um eco reverso por uma espécie de iminência de plural. Esta se projeta nas linhas que se vão acumulando, cabendo no espaço restrito e apertado do campo a elas destinado, mas já não mais cabendo neste mesmo espaço, expulsando as frases acima pelas frases que vão imperativamente ocupando as linhas abaixo. É como se tivéssemos epigramas cujos termos fossem não palavras, mas dicionários inteiros, como se pode ver no gerador de Pedro Barbosa:

Para perguntas arrogantes, perguntas em êxtase.

Quem faz perguntas cansadas, recebe respostas submarinas.

A excelência do saber está na paixão de saber perguntar.

O aluno faz perguntas exactas, o professor remói respostas na água. 
Em cada uma dessas linhas, então, seu fingimento de sentido fechado, essa obstinação pelo encurtamento, esse pendor ao epigramático está insinuando ou ecoando frases que já se entremostram abaixo, e frases que ainda nem mesmo surgiram na tela. E que talvez nem vão surgir. Aliás, o mínimo como eco do máximo (e vice-versa, o máximo como repercussão do mínimo) parece ser a nota dominante de um poema de E. M. de Melo e Castro, chamado justamente "O Eco e o Ícone":

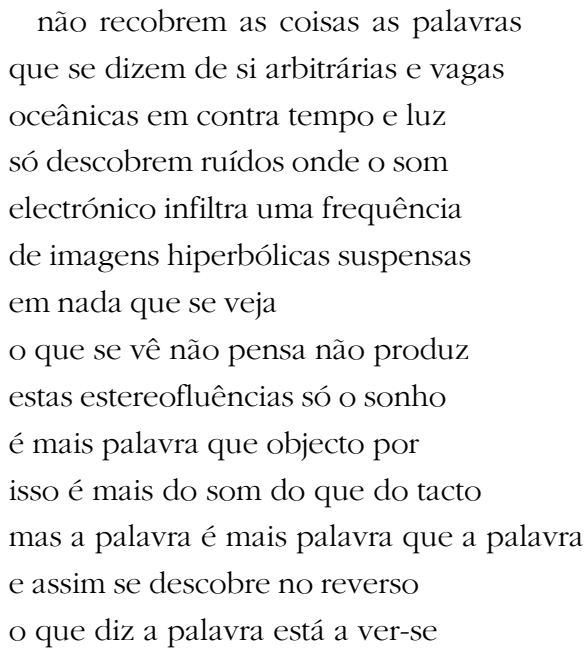

As palavras e as coisas não se recobrem umas às outras, não se substituem umas às outras. Elas se desdobram incessantemente: palavra em palavras, coisa em coisas, palavra em coisas, coisa em palavras. Embaixo de uma palavra já surge uma infinidade de coisas, e vice-versa, num processo a que não se dá fim. Todavia, pode-se dar a ele um descanso provisório, uma suspensão momentânea dessa pluralização incessante, quando ele se dá ao olhar: e assim se descobre no reverso / o que diz a palavra está a ver-se. Sílvia Laurentiz transformou esse poema de Melo e Castro em uma criação em VRML.' Primeira diferença a ser constatada e, também, explorada: à fluidez de movimentos permitida pelo olhar sobre a página imóvel (ou seja, a de papel, que nos permite rapidamente passar os olhos por cada um dos versos, de cima a baixo, de baixo a cima, ou vice-versa), se opõe a dificuldade de fazer com que os elementos em realidade virtual se movimentem pela tela do computador. De fato, a maioria

9. Disponível em <http://www.pucsp.br/pos/cos/interlab/in4/entrada.htm.> 
dos pluguins de VRML ainda traz vários incômodos, que vão da necessidade de aprender a manipulá-los (o que nem sempre é evidente, à primeira vista, para o leitor médio) à interatividade claudicante, dividida em vários ícones que perfazem, cada um e separadamente, distintas possibilidades de interação ou de movimentos. Como resultado, caímos num espaço de deslocamentos fragmentários, em que um dado movimento nunca é realizado em sua inteireza, ele é sempre o resultado da combinação de dois ou mais outros: ir de cima para baixo, aproximando-se ao mesmo tempo de uma das frases, exige ao menos a combinação, em instantes distintos, do ícone que comanda os movimentos verticais e daquele que comanda os horizontais. Num belo ensaio intitulado "Le langage indirect et les voix du silence", Merleau-Ponty fala da pintura de Matisse e diz que os gestos do pintor com o pincel não podem ser um movimento pensado, raciocinado e escolhido a partir de várias outras combinações possíveis de movimentos:

Une caméra a enregistré au ralenti de travail de Matisse. L'impression était prodigieuse (...) Ce même pinceau qui, vu à l'oeil nu, sautait d'un acte à l'autre, on le voyait méditer, (...) tenter dix mouvements possibles (...) et s'abattre enfin comme l'éclair sur le seul tracé nécessaire. Il y a, bien entendu, quelque chose d'artificiel dans cette analyse (...) Il n'a pas tenu, sous le regard de l'esprit, tous les gestes possibles, et pas eu besoin de les éliminer tous sauf un, en rendant raison de son choix. C'est le ralenti qui énumère les possibles.

Todavia, o movimento realizado e os movimentos possíveis não estariam no mesmo plano. Em outras palavras, estes últimos ficariam como pano-de-fundo, ou como conditions éparses sur le tableau, informulés, informulables pour tout autre que Matisse, puisqu'elles n'étaient définies et imposées que par l'intention de faire ce tableau-là qui n'existait pas encore. ${ }^{11}$ Ora, no caso da leitura em meio digital da criação de Silva Laurentiz, o que chama a atenção é justamente o fato de que há uma inversão: o movimento que leva direto ao ponto desejado da tela é que fica como pano-de-fundo; e são os movimentos possíveis e calculados que vêm à tona. E mais: entre aquele e estes, torna-se possível algum tipo de articulação, é possível estabelecer entre

10. Signes. Paris: Gallimard, 1960, p. 57.

11. Id. p, 58. 
eles alguma correspondência, como que uma vetorização, em que grandezas reais (a composição dos movimentos efetivamente realizados) e imaginárias (o movimento intuitivo e direto) se somariam de alguma forma.

De outro lado, cria-se um efeito de atraso, análogo ao ralenti mencionado acima por Merleau-Ponty: é como se cada um dos versos estivesse muito isolado, exigindo um esforço maior, uma série de operações para se passar de um a outro; como se eles todos estivessem afastados entre si por uma distância muito maior do que as entrelinhas da versão impressa. Em conseqüência, é a câmera-lenta que, estranhamente, se torna a maneira imediata e natural de estabelecer movimentos e de desenvolver gestos na tela do computador. Entretanto, ao contrário do espaço limitado da versão impressa - cabendo folgadamente no tamanho do campo de visão -, o espaço vazio e escuro que, na tela em VRML, fica ao fundo e, ao mesmo tempo, contorna as palavras, traz para o plano da experiência imediata a sensação do ilimitado, do inumerável, do indefinível. Em outras palavras, esse vazio traduz, na forma de uma ilusão de três dimensões, uma vertigem causada pelo horizonte de sentidos (e que se encontra na origem de todo significante e de todo significado). E tal vertigem é parente próxima de outra, a sensação que temos de lidar com uma infinidade de possíveis, vertigem tanto maior quanto mais explícita se torna. Daí a impression prodigieuse mencionada por MerleauPonty. Prodigiosa e assustadora, se nos faz pensar que todo movimento, todo gesto, toda expressão deveria ser encontrado em uma infinidade de possíveis, infinidade que, claro, sempre nos ultrapassa, que está sempre além de qualquer possibilidade nossa. Daí vem o esforço de incorporar o acaso a toda expressão artística contemporânea. É como se se afirmasse que, sem ele, não haveria qualquer esperança de se encontrar o movimento adequado, o gesto cabível, a expressão possível. Contudo, em Mallarmé, podemos aprender que se trata justamente do contrário. Schérer afirma que Il faut éliminer le hasard des mots, dont chacun est constitué par une alliance contingente, et parfois perverse, entre un son et son sens. ${ }^{12}$ No Livre, parece que Mallarmé justamente procura eliminar o acaso, através de uma multiplicação desmesurada... do próprio acaso. Ao contrário das vanguardas e da arte contemporânea - com seu culto à casualidade -, ou dos surrealistas com seu acaso objetivo, o Livre de Mallarmé

12. Op. cit., p. XVI. 
est abolition du hasard par son projet même. (...) il montre que le hasard n'y a point sa place habituelle. Pour l'éliminer plus radicalement encore, le Livre refuse la passivité de la continuité unilinéaire et se développe dans un hyper-espace à un grand nombre de dimensions comme en ont imaginé les géométries non euclidiennes. Ces nombreux ordres ont pour fonction de soumettre à leur ordre la contingence qui est le péché du langage. "Pecado da linguagem" ou, dito de outra forma, vertigem causada pela infinitude dos sentidos possíveis e experimentada pelo efeito de câmera-lenta explicitada pelas incursões em espaços como a criação VRML de Sílvia Laurentiz.

Voltando ao que se dizia acima da câmera-lenta, nessa retomada digital do poema de Melo e Castro temos uma estranha inversão, que faz da vagareza pensada e planejada o gesto menos penoso, o movimento mais imediato; em contrapartida, a fluidez do movimento direto buscaria o percurso mais difícil e mais custoso. Todavia, se não podemos escapar da primeira, não devemos ignorar a possibilidade (mesmo nunca concretizada) do segundo. De fato, embora não sendo efetivado, este último (ou seja, o movimento direto e fluido) permanece como horizonte de possibilidade. É como se nosso exercício imediato do espaço digital, dos comandos de VRML, exigisse a presença a distância - ausente, quase diríamos -, desse movimento que, na tela e através dos comandos e interações disponíveis, é impossível de ser exercido efetivamente. Ou, dito de outra maneira, ele só se efetiva como exercício indireto de uma impossibilidade. De todo modo, há entre os dois movimentos - o que tentamos e fazemos, e aquele que intencionamos e não realizamos uma coexistência a distância, uma mútua interferência, retomando novamente o esquema vetorial exposto algumas páginas atrás. Fazendo analogia com os números complexos, o movimento realizado estaria no eixo dos números reais, enquanto que o movimento não efetivo estaria situado no eixo dos imaginários.

Todavia, como já comentado, essas dualidades são inúmeras e parece claro que umas ainda podem interferir em outras, o que resultaria num esquema complicadíssimo se quiséssemos expô-lo num desenho de duas ou de três dimensões. Chegaríamos rapidamente a um ponto em que nenhum gráfico ou esquema daria conta de reproduzir os elementos e as operações mais

13. Op. cit., p. XVII. 
importantes, e teríamos que fazer isso lançando mão de equações matemáticas, o que nos levaria longe demais de nosso propósito. Podemos pensar, então, em reduzir essas dualidades àquelas mais importantes, mas ainda tentando dar conta de tudo o que de mais importante se tentou discutir até aqui. O resultado é um esquema mais ou menos simplificado (e simplificador, como o são todos) que congregue obra, texto, leituras, produtores de significantes, significantes produzidos e significações. Ele ficaria com o seguinte aspecto:

No plano da obra, isto é, de sua materialidade, temos uma conjunção (ou soma vetorial) entre os mecanismos de produção de significantes ( $\mathrm{y}_{\mathrm{o}}$ - no Sintext, são as estratégias e as linhas de programação) e os próprios

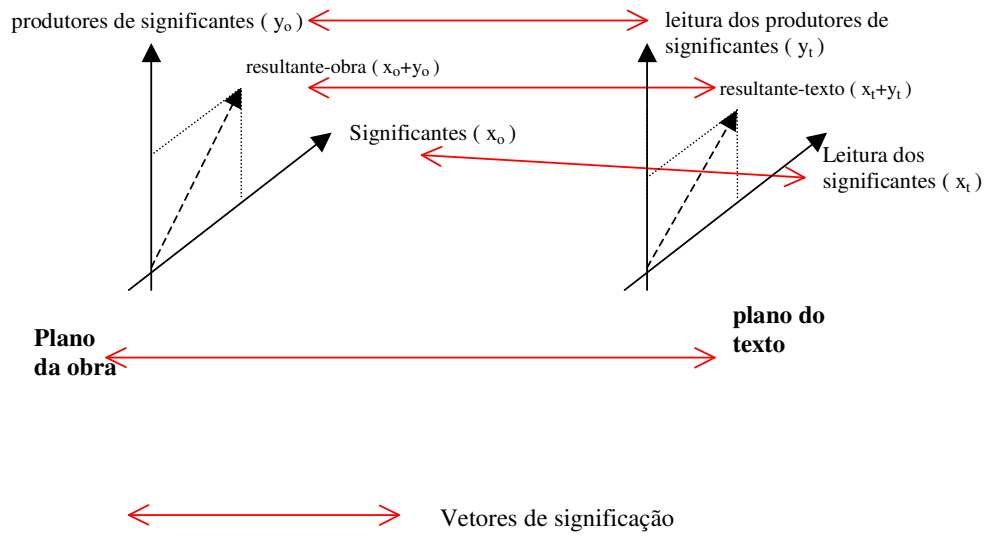

significantes ( $\mathrm{x}_{\mathrm{o}}$ - as frases que vão sendo geradas). Não se pode dizer que a obra seja apenas uns ou outros, nem uns e outros, mas uma resultante-obra $\left(\mathrm{x}_{\mathrm{o}}+\mathrm{y}_{\mathrm{o}}\right)$ que estará no espaço intermediário entre produtores e significantes. No plano do texto, isto é, daquilo que resulta de leituras, vamos ver outra conjunção, dessa vez entre a leitura que fazemos dos produtores de significantes ( $\mathrm{y}_{\mathrm{t}}$ ) e a leitura que fazemos dos próprios significantes $\left(\mathrm{x}_{\mathrm{t}}\right.$ ). Novamente, não se pode afirmar que o texto seja resultante apenas de uma ou de outra, nem de uma e de outra; ele estará nessa região intermediária entre uma leitura e outra, nisso que chamamos de resultante-texto $\left(\mathrm{x}_{\mathrm{t}+} \mathrm{y}_{\mathrm{t}}\right)$. Todavia, as dualidades não param aí, pois, a partir do mapeamento desses dois planos (obra e texto), é possível propor exercícios de significação (ou seja, também somas vetoriais) que partam justamente dos eixos correspondentes em cada um deles. Assim, estaríamos discutindo significados 
possíveis a partir dessa linha (ou soma vetorial) que leva dos produtores de significantes $\left(\mathrm{y}_{\mathrm{o}}\right)$ a sua leitura $\left(\mathrm{y}_{\mathrm{p}}\right)$; dos significantes produzidos $\left(\mathrm{x}_{\mathrm{o}}\right)$ a sua leitura $\left(\mathrm{x}_{\mathrm{t}}\right)$; da resultante-obra $\left(\mathrm{x}_{\mathrm{o}}+\mathrm{y}_{\mathrm{o}}\right)$ à resultante-texto $\left(\mathrm{x}_{\mathrm{t}}+\mathrm{y}_{\mathrm{t}}\right)$; finalmente, do plano da obra ao plano do texto. E podemos sofisticar (e, claro, complicar) ainda mais o esquema, se introduzimos outra dualidade, aquela que se dá entre autor e leitor. No caso, um esquema tridimensional não mais daria conta de representar, mesmo precariamente, as possibilidades todas e teríamos de lançar mão de uma simulação em quatro dimensões, o que somente seria possível com o apelo a equações matemáticas (como já dito acima).

Por outro lado, não estamos aqui cometendo a temeridade de afirmar que se pode resolver a questão da leitura de obras artísticas no espaço digital por um apelo a cálculos vetoriais; nem mesmo que devemos nos pôr a fazer tais cálculos. Estes esquemas tentam dar, paradoxalmente, uma imagem menos esquemática de questões muito complexas, apontando algumas possibilidades com que tratar os elementos e as operações envolvidas. De fato, essa tentativa de colocá-los todos - elementos e operações - em espaços de eixos coordenados, em espaços vetorizados, parece nos encaminhar para uma espécie de topologização, por mais simples que ela seja. No caso, queremos dizer que pode ser interessante começar a pensar neles em termos de vizinhanças, de limites etc. Porém, tal vetorização e tal topologização não pretendem se tornar uma máquina de gerar estratégias, ferramentas e resultados de leitura. Nem mesmo se pretende insinuar que topologização, esquematização ou vetorização dêem origem a conceitos, a partir dos quais se leia, se compreenda e se classifique qualquer obra digital. Em outras palavras, os vetores de significação, sugeridos no esquema acima, não são fabricados por uma outra máquina - a de produzir conceitos $^{14}-$ que meteríamos por cima do computador. No caso, é importante pensarmos não em conceitos prontos e acabados, definitivos em sua ação de pôr cobro e dar meta às reflexões, mas como operadores conceituais. Através destes, se tenta dar conta de movimentos e de gestos de pensamento. Assim, em vez de conceitos, sempre prontos e acabados, quer-se exprimir movimentos conceituais, numa espacialização-vetorização do pensamento que é também a espacializaçãovetorização que se pode associar a qualquer gesto expressivo. ${ }^{15}$ Assim, quando se

14. Parafraseando Oswald de Andrade, posso dizer que não se está inventando uma máquina de fazer conceitos - já temos o ensaísta pós-moderno. 
falou de dualidades, mais do que buscar sua resolução em sínteses simplistas, mais do que se fixar em maniqueísmos irredutíveis, quis-se multiplicar ao máximo tais instâncias de duplicidades, pluralizando, em cada elemento e a cada processo, as dissonâncias resultantes dessa multiplicação de dualidades.

Se fôssemos propor algumas linhas de conclusão, poderíamos dizer então que se tentou aqui sugerir alguns movimentos conceituais, a partir de elementos e de processos do espaço digital, quando se trata de ler obras artística criadas nele e por ele. A utilização do esquema vetorial acima, mesmo dando conta das dualidades mais simples, já traz uma complicação excessiva, impedindo quase uma compreensão e uma experimentação efetiva do objeto artístico digital. Ora, a saída poderia ser a metaforização e, habitualmente, ela tem sido feita a partir das imagens do labirinto e do rizoma. Contudo, ambas parecem ter esgotado boa parte de seu potencial de agudização do espírito e de renovação da sensibilidade. É por isso que se busca aqui uma posição ainda aquém de qualquer metaforização (esta não deixa ainda de ser um processo que envolve sempre o desenvolvimento de conceitos com um mínimo de coerência reflexivo, de validade argumentativa, de acabamento formal). Em vez de labirinto ou de rizoma, propõe-se tomar não propriamente a imagem, mas a topologia da Fita de Moebius. No caso, ela daria a aparência, no espaço de três dimensões, desses movimentos de operadores conceituais que aqui tentamos descrever e experimentar: da mesma maneira como ela - a Fita - faz a passagem do plano ao espaço e do espaço ao plano (e do tempo ao espaço, e do espaço ao tempo), os operadores conceituais permitem passar, também nos dois sentidos, de um termo a outro das diferentes dualidades que compõe o espaço digital, sem estabelecer entre eles nenhuma prioridade ou anterioridade. E o Livre me pareceu, desde o início, o proto-espaço de

15. Nesse caso, a literatura estaria em posição ímpar, por aguçar o espaço da língua através de dobras da linguagem (nesse caso, a linguagem seria o operador conceitual que atua na língua). A literatura seria então o espaço privilegiado onde se geram e utilizam tais operadores (processos, operações), Em suma, a literatura sempre foi, ela própria, movimento conceitual (e jamais conceitos prontos e terminados, mas sempre um constante aquém de conceitos e de idéias - daí o motivo por que toda história ideológica da literatura sempre esbarra em alguma impossibilidade -).

Movimentos ou, dito de outro modo, operadores conceituais, como os que se sugeriu aqui, não são, portanto, conceitos. Justamente quando se passa dos movimentos aos conceitos, já se está fora das artes. A partir daqueles é que se pode, eventualmente, chegar a estes, num percurso cujo espaço privilegiado é o das artes e, dentre elas, o da literatura desponta como o mais importante. 
experimentação desses movimentos conceituais todos: como pensar um gesto expressivo que não abole propriamente sua contingência, seus acasos, mas os reduz a seus próprios elementos, estratégias e processos, sem ser através de uma reversibilidade?! É precisamente isso que me interessou na criação de Mallarmé e no espaço digital: uma contingência fechada e um acaso absoluto que se revelam ilusórios; em outras palavras, uma exterioridade que não deixa nunca de se reafirmar no mesmo movimento e momento em que se reduz à interioridade (e vice-versa). Poderíamos até arriscar que o Livre, a Fita de Moebius e o espaço digital são constatações ou experiências, talvez diretas, daquilo que Merleau-Ponty, em Le Visible et l'invisible chama de quiasma ou reversibilidade. Mas isso me parece ir muito longe, certamente mais do que me permite a exigüidade deste espaço. Para terminar ou, melhor, para suspender momentaneamente essa discussão, volto, ainda uma vez mais, ao que Jacques Schérer disse do Livre de Mallarmé: Comment prouver le Livre? Il ne peut ressembler à rien qui lui soit extérieur. Ce n'est qu'en lui (...) qu'il trouvera sa propre preuve. Elle est parfaite et totale, puisque rien de la contingence extérieure, qui pourtant alimente le Livre, ne peut parvenir jusqu'à son cour et le vicier. C'est pourquoi le monde existe pour aboutir à un Livre. Il ne peut aboutir à rien d'autre qu'à un Livre, et à ce Livre même de Mallarmé..$^{16} \mathrm{E}$ ainda, mais longe, Schérer vai mesmo falar de uma dimensão ritual, talvez quase religiosa, do Livre, o que o faz propor uma dramatização da obra de Mallarmé (coisa que ela realiza efetivamente). É esse caráter de experiência direta, de ritual secularizado que me parece também interessante, dando outra feição à velha metáfora do mundo-como-livro. Ela se desenvolve agora na direção de outra metáfora, também vestusta, a do mundo-como-teatro. Se o mundo existe para acabar num livro, ele também existe para ser posto num palco. Todavia, ao contrário de época anteriores (podemos citar o Renascimento, com relação à primeira metáfora; o Barroco, com relação à segunda), no Livre, livro e teatro não se excluem nem se anulam. Ambos concorrem para um topologia extremamente complexa em que obra e texto se alimentam, se provocam, se tornam mais e mais complexos, num jogo de espelhos cujo fundo, infinito, não se vê mas se pressente. Não seria essa uma descrição aproximada do espaço digital, quando habitado e imantado pela criação artística?! Como no Livre, é possível

16. Id., p. XVIII. 
que a criação digital seja, ela também, a ocasião de uma coniunctio entre livro e teatro, entre obra e texto, entre hipertexto e ritual, como foi o caso, acima, entre obra e texto, entre produtores e significantes... E essas dualidades não param, alimentandose umas às outras, despertando umas às outras, estendendo indefinidamente umas às outras. De fato, entre uma obra que nunca alcança um texto, um texto que nunca se fixa em obra, apenas a encenação de Livro e Obra pode resultar em uma leitura efetiva. Como disse o próprio Mallarmé na epígrafe deste trabalho, algo que não começa, nem termina, só pode existir se faz de seu início e de seu fim pura encenação. Nem que seja uma certa encenação de conceitos, como o que se quis fazer aqui.

Abstract: The digital medium, as is widely known, has altered both in quantity and in quality the materiality of the literary works one may happen to read. This article proposes that the reading of digital creative texts demands more than mere literacy and common knowledge of computers and nets. There is complexity to be unfolded, sophistication to get used to by these readers when they set out to explore the digital space.

Key words: Mallarmé, digital programming, Melo e Castro. 